\title{
Article
}

\section{The Multilingual Turn in a Tutor Education Course: Using Threshold Concepts and Reflective Portfolios}

Hidy Basta

Seattle University

\begin{abstract}
In this article, I reflect on efforts to revise the instruction and evaluation of an undergraduate writing consultant education course. The revisions are motivated by the desire to adopt practices that reflect the writing center's commitment to social justice for multilingual/translingual students and by a commitment to provide an effective, flexible, and brave environment for writing consultants to continue their professional development. I argue that grounding understanding of multilingual writers in concepts that explicitly explore linguistic diversity and standardized ${ }^{1}$ English ideologies as threshold concepts is essential to reconceptualize writing center practices. I also argue for the necessity of adopting a flexible system for reflection, engagement, and evaluation to support writing consultants' learning and practice. I share prompts used in the course and some of the responses they generated. The responses suggest that although combining threshold concepts with a portfolio system is successful in supporting inclusive practices, there remains a need to expand more inclusive practices across the university.
\end{abstract}

Keywords: Tutor education; writing center; multilingual writers; linguistic diversity; multilingualism as a threshold concept

\footnotetext{
${ }^{1}$ Greenfield's adaptation of the term "standardized" instead of "standard" is helpful as it brings attention to the human activity deciding on the varieties that are privileged as "standard." For a detailed discussion, see Greenfield (2011).
} 
Volume 30, 2020

http://journals.sfu.ca/cjsdw

\section{Introduction}

Although I have yet to meet a writing center consultant ${ }^{2}$ who does not agree on the importance of honoring students' right to their own languages and the importance of maintaining inclusive practices, I have witnessed numerous practices that maintain the status quo of privileging a monolingual approach to academic writing. Despite the best intentions to be an inclusive writing center, legacies of linguistic oppression are echoed in handouts, policies, and practices.

Critical scholarship reminds us of the role a writing center can play in perpetuating and/or resisting monolingual/monocultural dominance (e.g. Bawarshi \& Pelkowski, 1999; Denny, 2010; Greenfield, \& Rowan, 2011; Greenfield, 2019, Grimm, 1999; 2009). While current writing center guides and handbooks advocate for inclusive approaches to support multilingual writers, the practices continue to cast multilingual writers as either challenging clients with additional needs or vulnerable students. The practical approaches to consultations seldom draw on multilingualism as a valuable linguistic resource and a reality of a global context. Greenfield \& Rowan's (2011) chapter argues that this approach to linguistic diversity is more of a "week twelve" approach, where the issue of other languages and dialects is introduced as a special case that is different from the expected norm of the academy.

I focus on addressing this gap between theories and praxis in consultants' education for multiple reasons: (1) Tutor training offers a clear reflection on how the field reinscribes/shapes the goals of the writing center and the role of tutors and students. The market is rich with training manuals, tutor guides, and handbooks that explicitly and implicitly reflect the values we see as important to pass on to new practitioners (2) Peer consultants are the main players in the writing center. Supporting their practice is a direct way to influence their clients' experience. (3) Writing consultants demand an explicit and supportive education--one that enables them to thoughtfully navigate the complexities of working with multilingual writers.

Here, I share the story of my experience in revising writing consultants' education course. I reflect on materials and writing prompts I have shared with the consultants, their uptake of the prompts, and our collective desire to contribute to the university's work to support multilingual students. I

\footnotetext{
2 I use the terms "writing consultants" and "writing tutors" interchangeably. The writing center I direct uses the term writing consultants.
} 
Volume 30, 2020

http://journals.sfu.ca/cjsdw

hope that sharing this experience adds to the expanding body of literature on tutor education in antioppressive pedagogies. The first part of the article focuses on the narrative of the writing center and draws on the literature that motivated the revisions I have made to the curriculum ${ }^{3}$. The second proceeds to share an assignment prompt and selected responses from the writing consultants. The third offers an analysis of these responses and argues for the capacity of threshold concepts to change practices and for the necessity of nurturing a flexible learning context that allows for mistakes, vulnerability, and unlearning. The conclusion discusses ongoing efforts and explores the potential for collaborative relationships across campus to promote inclusive teaching and evaluation of writing.

\section{Our Writing Center Narrative}

Our institution is a mid-size private liberal arts Jesuit university located in a metropolitan city in the United States. The writing center was established in 1987 as a part of an initiative to support writing across the curriculum. The university's mission statement is grounded in social justice and professional formation. As such, the writing center was able to easily align its goals for social justice rhetorically with the university's mission statement as an institutionally sanctioned goal. While the commitment to the mission is unified, approaches on how to best accomplish it remain contested. The campus community often holds the university accountable to its ideals. The undergraduate consultants' education is considered a valuable component of their "professional development toward a just and humane world."

Not unlike the history of writing center practices (see Boquet, 1999; Carino, 1995), our writing center has experienced a progression of different practices on how to best conduct writing tutorials. The center's practices and the language used to describe them have evolved as the field has. When I was hired to direct the center in Fall 2017, I was naively surprised to see a mix of competing strategies for conducting writing consultations. The artifacts of the writing center and the conversations with returning consultants echoed these competing strategies. Approaches to drill lab/error free/leveling the playing field goals coexisted with the hands-off approaches to non-directive/minimalist tutoring. The expectations of writing center clients and faculty differed widely as well.

The current consultants were either invested in the role of the writing center as a drill lab to fix

\footnotetext{
3 The curriculum revisions included other elements such as mock sessions and group projects including research papers; my analysis here is limited to the elements that were grounded in consultants' reflection and assessment of their learning.
} 
Volume 30, 2020

http://journals.sfu.ca/cjsdw

grammatical errors, or as a non-directive/minimalist tutoring space designed to make the writer do all the work (Brooks, 1991). As part of welcoming me, the consultants shared their concerns about the different training each cohort had received. In the previous three years, they were trained by four different directors. The consultants were eager to bring stability to the center and to offer a unified practice. According to them, the task at hand became for me to choose a practice and make them stick to it.

The English department was clear in articulating my task. I was to design an inclusive course that addresses issues of diversity, privilege, and inclusion--issues that the university was grappling with and fully committed to address. The department believed that I could be quite successful in this role of advocacy as an academic of color who is passionate about inclusion. I had hoped for the consultants' education to reach beyond the dichotomy of the directive/non-directive approach. To facilitate this shift, I drew on Harry Denny's (2010) framework for queering the center and challenging the dichotomies that plague it.

Denny notes that "Writing centers are places overflowing with structuring binaries: directive/nondirective, [...] expert/novice, [...] American/ESL, [...] advanced/basic, etc. These binaries and their negotiation of which side is privileged, and which is illegitimate are ubiquitous in sessions" (p. 97). I believed that an ideal education should develop flexible heuristics to question the dichotomies and to continue to reflect on making our commitment to social justice actionable. I introduced other frameworks which were based on the multicultural, translingual turn in composition studies, ones that normalized the different Englishes and dialects and went beyond the assimilationist policies of colonial pedagogies (Bawarshi and Pelkowski, 1999; Canagarajah, 2006, 2013; Grimm 2009; Horner, NeCamp, \& Donahue, 2011).

These strategies, while promising, proved to be even more challenging and confusing to both new and returning writing consultants. By focusing on inclusive practices that honor multilingualism, dialects, and multimodality, the tutors lost essential credit as linguistic privilege did not legitimize their position as helpful tutors. If being a "good writer" is no longer the first job requirement for a tutor, then what is? The unintended consequence of destabilizing the dichotomies was the destabilization of the consultants' sense of confidence of what constitutes good writing. If they defined their experience as writers as good because they knew how to use grammar well (read White standardized English), then what qualifies them and what training can nurture them? This failure 
Volume 30, 2020

http://journals.sfu.ca/cjsdw

was the beginning of a journey of communication, reflection, and course revisions.

Centering multilingualism and World Englishes destabilized the writing center practice and the goal of consultations as well. Consultants who supported students in editing their papers according to expectations of standardized English felt bad about taking over the paper, while consultants who focused on global issues felt that they have short-changed their clients by ignoring legitimate concerns about sentence level issues. What is the goal of the writing center, then? What is it that we do when we declare "we support multilingual writers?"

Our writing center has inherited a legacy of standard language ideology that accepts a rigid view of literacy as monolingual. Indeed, an older description of the course remained in the course enrollment system. I took it as a reminder of the course's genesis as “[p]ractical training for students chosen to be tutors in the Writing Center. [...] Strategies for diagnosing writing problems, mastering effective conferencing skills to help writers reduce anxiety, generate ideas, solve organizational problems, and develop a fluent, error-free prose style." (internal site)

The description echoes language that pathologized writing "problems," advocated for "mastery" to help develop "error-free prose style." The description assumed one academic style sanctioned by the university as the norm. The goal of tutor "training” captures what Bawarshi \& Pelkowski (1999) describe as the role of the writing center in reproducing colonialist approaches for understanding students and how to best "change" them. It became necessary for us to collectively examine the implicit assumptions that motivate our work with writers.

My goal for revision was to (1) facilitate meaningful reflections on readings which integrate concepts of multilingualism/multiliteracies and English language ideologies, and (2) to use an evaluation method that makes space for brave and transformative learning that happens over time.

I'm grateful to the dedicated peer consultants of Fall 2017 who met with me, participated in focus groups, filled out surveys, invited me to observe their sessions and spoke honestly about their frustrations in staff meetings and class sessions. Their honest feedback and thoughtful reflections brought much insight to what it means to challenge monolingual norms in academic discourse. Revising the course in collaboration with them has been a cherished experience that has embodied the productive potential for writing center consultants to maintain an active agency in their education. 
Volume 30, 2020

http://journals.sfu.ca/cjsdw

\section{Writing Consultants' Education in the Twenty-First Century}

Although the market is rich with tutor handbooks that offer valuable advice on how to best support multilingual writers, they tend to privilege a monolingual/ monocultural stance that inadvertently marginalizes multilingual consultants and their multilingual clients. Bailey (2012) offers a thoughtful critique of current writing center handbooks. His analysis demonstrates that monocultural and monolingual assumptions "remain deeply embedded in the discourse of generation 2.0 tutor handbooks" (p.5). The analysis demonstrates that these handbooks tend to offer a U.S. centric focus and to introduce the tutors as cultural insiders and linguistic informers with ethos to "fix" the problems of English Language Learners (ELL). This approach privileges monolingual native English speakers. On the infrequent occasions when a multilingual or an international student appears in these handbooks as the tutor, they are discussed as a "tutoring problem" (p.6) since clients see them as unreliable cultural and linguistic informants. Bailey calls for a generation 3.0 of handbooks which could position multilingualism as the norm. Indeed, a handbook or any tutor education program needs to adopt an understanding of diversity and multilingualism as a linguistic norm and as a resource. Pointing out that even handbooks can center monolingualism is essential in understanding the systemic nature of language oppression and the need to resist it.

Nancy Grimm's (2009) call is to replace conceptual frameworks with inclusive ones. She summarizes arguments on the ways in which our unconscious framework explains our practices toward students, language, literacy and culture. She observes that throughout the history of writing centers (including her own and certainly ours), the location, practices, policies, and tutor education continue to change. These changes reflect unconscious and conscious understanding of language, students, literacy, and I would argue the goal of education. Grimm convincingly argues that "change in any workplace happens when unconscious conceptual models are brought to the surface and replaced by conscious ones" (p.16). Grimm introduces three frameworks that have since inspired tutor education programs: 1) a framework of working within the context of global Englishes, 2) a framework where literacy is understood as the ability to negotiate more than one discourse system and more than one mode of representation, and 3) a framework that understands students as the designers of social futures. Contextualizing and normalizing writing center changes is liberating as it enables viewing the practices as flexible and subject to revision in order to respond well to current contexts. 
Volume 30, 2020

http://journals.sfu.ca/cjsdw

More specifically, Greenfield (2019) centers the goal of tutor education as a critical space to question implicit assumptions and monolingual frameworks. She argues for a radical practice in which "tutoring [is] a process that requires life-long study, reflection, collaboration, and reinvention" (p.145). The radical practice requires questioning the lore of writing centers and their practices. Instead of thinking of ESL writers as atypical, we can "problematize the ways monolingual English speakers are made central and normative in writing center discourse" (p. 149). This critical question rejects the reductive narratives that frame the difficulties of working with multilingual writers in terms of linguistic deficits or poor preparation for college writing. Instead, it locates the limitation to centering and normalizing monolingual English speakers and ignoring multilingualism as linguistic resources.

Multiple scholars in linguistics and composition studies have successfully argued for adapting pedagogies and policies that honor multilingualism as a resource, rather than a problem to be fixed. Canagarajah (2006) demonstrates the rich context of the ability of multilingual writers to shuttle between languages with intentionality, sensitivity to audience, context, and personal goals. Multilingualism is not a communicative liability to be mitigated. Donahue (2016) demonstrates the rhetorical flexibility in translingual-transnational writers. Greenfield (2011) expands on LippiGreen's (2012, 1997,1 1st ed.) arguments that expose the "fairytale" of "standard" English and question the racist commonplace assumptions about language diversity. Smitherman \& Villanueva's (2003) edited collection is rich with arguments and practical resources to support language diversity. Even with the increasing calls for antiracist assessments of writing (Inoue, 2015), standard "error-free" writing remains a major criterion in grading. Deborah Cameron's observation over two decades ago that "linguistic bigotry is one of the last publicly expressible prejudices left to members of western intelligentsia" (1995, p. 12) remains a relevant reality today.

Published journal articles on writing center scholarship, conference proceedings, and edited collections provide rich resources to support inclusivity and social justice, yet practices remain problematic and complicit in the continued exclusion of multilingual writers. The need remains to dismantle current frameworks that are inherent in writing center practice and to replace them with conscious frameworks. In doing this work, I'm inspired by the terms used throughout writing center scholarship to capture this type of practice. Sarah Blazer (2015) refers to it as a "transformative ethos", Nancy Grimm (1999) refers to it as "relentless reflection," Laura Greenfield (2019) describes it as "radical praxis." 
Volume 30, 2020

http://journals.sfu.ca/cjsdw

\section{Threshold Concepts and Transformative Learning}

The purpose of a tutor's education is not to simply transfer knowledge, guidelines, and policies to enact and reproduce the center with each writing consultation. Effective tutor education programs tend to focus on affording engaged professional development that holds a promise to change the participants and their practice (Greenfield, 2019). Two common strategies used for this transformative type of professional development have been (1) reflection on engaged practice (eg. Blazer, 2015; Hall, 2011); (2) engaging in research as a way to understand and inform practice (eg.Fitzgerald \& Ianetta, 2016; Nakamaru, 2010). My revised course focused on the potential of threshold concepts to create space to learn new conceptual frameworks and to facilitate engaged reflections.

\section{The Revised Center}

Using Linda Alder-Kassner and Elizabeth Wardle's (2015) framework of threshold concepts of writing studies facilitated this transformative work toward situating multilingual literacies by allowing a deconstruction of what it means to support linguistic diversity. Adler-Kassner and Wardle use Meyer and Land's (2006) (as cited in Alder-Kassner \& Wardle, 2015) description of the common characteristics of threshold concepts as transformative in the way they involve conceptual shifts; once understood they are unlikely to be forgotten, and once learned they are integrated in learners' understanding of how phenomena are related. The description also highlights that learning threshold concepts is about learning "troublesome knowledge" that seems to be counter intuitive. Threshold framework ${ }^{4}$ lends itself appropriate to grounding writing center practices in appreciating linguistic diversity as a resource rather than a problem and actively engaging in anti-oppressive practices.

Establishing a brave learning environment where the consultant can examine assumptions, work with troublesome knowledge, and change positions and practices required a learning assessment system that doesn't assume instantaneous and discrete learning. To this end, I used a portfolio system where consultants can choose to revisit and revise work done at any stage of the quarter. The portfolios reflected the fluid reality of ongoing learning that is flexible enough to integrate new

\footnotetext{
${ }^{4}$ For additional examples of using threshold concept in consultant education see Norwacek \& Hughes (2015), which found the concept effective in scaffolding tutor expertise in understanding writing process, and Sue Dinitz (2018), which explored a practical approach of changing tutors threshold concepts of writing through doing multi-draft writing assignments in genres and contexts that are new to the tutors.
} 
Volume 30, 2020

http://journals.sfu.ca/cjsdw

knowledge and experiences. They prompted the consultants to (re)examine previous experiences in light of new ones, which normalized shifts in thinking and practices.

\section{Tracking Threshold Concepts in Reading Reflections}

To support consultants' understanding of linguistic diversity, I invited them to select one of three articles to read and reflect on. Figure 1 introduces this assignment.

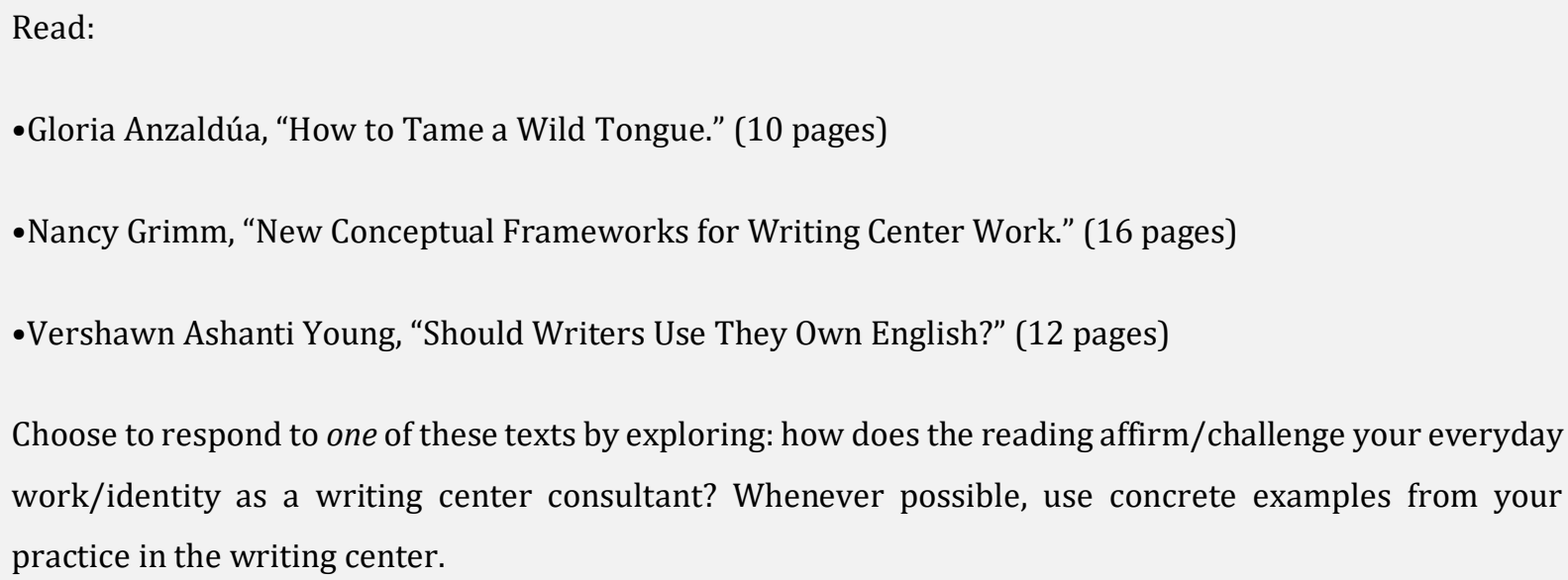

Figure 1. Linguistic Diversity \& What it Means to Our Practice

Gloria Anzaldúa's "How to Tame a Wild Tongue" introduced consultants to the ways in which identity is intertwined with language. Nancy Grimm's "New Conceptual Frameworks for Writing Center Work in the 21st-Century" provided a historical context to writing center work and how it continues to progress. It encouraged the consultants to consider the complexities of the linguistic choices in a global context and to think of literacy as the ability to negotiate multiple discourses. Vershawn Ashanti Young's article written in African American Vernacular (AAVE), "Should Writers Use They Own English?," offered an example of a sound argument for and an enactment of code meshing. In offering a choice of which of these texts to respond to, I hoped that consultants would be free to select aspects that they find interesting. As we read and discussed the responses in our class sessions, the consultants were also exposed to others' reflections on the additional texts. I analyzed the responses to identify the threshold concepts they named. The questions that led my analysis were: What did they identify as new knowledge? In what ways was it troublesome? And how did they imagine integrating it in their practice? 
Volume 30, 2020

http://journals.sfu.ca/cjsdw

\section{Consultants Responses to the Readings}

It's worth noting that not all consultants engaged equally in the readings. The reflections from four consultants who have allowed me to share their writing anonymously ${ }^{5}$ show deeper and more personal engagement. The consultants captured a sense of conceptual shifts in using words such as struck, surprised, and amazed as markers for new knowledge. New knowledge is also marked by phrases such as "I now realize, I never knew, and no one else told me." In all four examples discussed here, the consultants identified new knowledge, reflected on their identities and histories, and expressed commitment to new practices.

Candace's Response:

When I encounter students who write in dialects of English that are not conventional or considered "academic", I have to remind myself that English is a language that has rules and standards, yet those are meant to be challenged and brought up to speed with people's lived experience.

While I know this concept, and understand it, I am still working on un-learning my old way of thinking about English and its rules that must be followed. In each session I do my best to preserve the writer's voice as they have written it, while checking for clarity within structure and grammar. Grammar and spelling matter because they can change the meaning of what has been written. However, if I notice a small error that does not affect the meaning of the writing, I consider letting it be. I make this decision based on whether the writer has asked me to bring those small details to their attention or not.

I believe that English has the potential to shift its norms to accept other dialects as the new standard and convention of the language. But in order for this to happen, people have to be willing to intentionally normalize what is now considered to be "non-standard". And as I mentioned before, this only works in cases where the writer is also willing to write in their own dialect as a stylistic choice. For higher-stakes writing such as grants and applications, this process of normalization might take a bit longer.

Candace's Response identifies language change as a threshold concept. She acknowledges that users are in a continuous process of changing language. The fact that living languages continue to change competes with her understanding of "rules must be followed." Candance identifies the need

${ }^{5}$ The names used here are pseudonyms. The consultants provided written permission to use their materials. The Institutional Review Board (IRB) has determined the study to be exempt from review in accordance with U.S. federal regulation criteria. 
Volume 30, 2020

http://journals.sfu.ca/cjsdw

to work intentionally to unlearn previously held beliefs and to question the status of standardized English. To guide her practice, Candace draws on a client's goals of the session and on whether the genre allows for diversions (whether it's high stakes writing). Candace's question captures her sense of responsibility toward the client. The promising aspect is her call to normalize what is now considered to be "non-standard." She concludes with the sobering realization that this process "might" take a "bit longer." Her response reflects the emergence of an understanding that challenges a monolithic notion of literacy, yet balances its appropriateness with whether the context is "high stakes."

Tessa's Response:

I also was struck by the notion that not all language-learners' experiences are the same. In other words, depending sometimes on the language being learned, the learner's identity (whether or not it is selfidentified), or the place a language is being learned, some peoples' language acquisition is celebrated and others['] is marginalized. For example, when I went abroad to Berlin I made the decision to learn German. Both there and here in the United States, my choice to learn a new language was celebrated as me broadening my cultural understanding and making strides in terms of how marketable I am to future employers. On the other hand, many students who come to the United States as English language learners are met with responses that question and criticize their ability. They are met with the notion that everyone in the United States should inherently know and be able to speak standard "American English" perfectly. It is a similar case with accents. The American Orientalist gaze views "white accents" such as British, French etc. as beautiful, trendy, and worthy of replication but in the same vein it criticizes those who speak with accents they identify as non-Western.

Tessa's response brings into question the racist prejudices against English language learners. She argues that language assessment is not completely about language proficiency, because learning another language abroad is not at all stigmatized (while learning English in the US can be). Her critical analysis that not all learners and accents are treated equally makes a case against racially based bias in language evaluation. As Deborah Cameron argues in Verbal Hygiene, standard English remains the last institutionally sanctioned discrimination even/especially in education (Cameron, 1995). While Tessa's response didn't explore the implication of this realization on her work as a writing consultant, her work continued to push against norms that penalized ESL students for not being native speakers of English rather than celebrating their multiple discourses. 
Volume 30, 2020

http://journals.sfu.ca/cjsdw

Andie's Response:

While reading Gloria Anzaldúa's essay, "How to Tame a Wild Tongue”, I was struck by the idea that language can both be a way of bridging gaps/blurring lines of difference as well as a means of disassociating from one another. While Anzaldúa explains that her language connects her to others and to history, she also examines how the variances in Spanish and the oppression of the language by the English-speaking power structures have separated her from both the English-speaking world as well as from other Spanish-speaking people. Language is neutral, but the way that we approach it and the way that we attempt to bridge gaps can either build walls between people or tear them down. This challenges the way that I approach my consultations in the Writing Center, for I want to use the differences in language to blur lines of difference, not to create them. Though I have no[t] necessarily figured out the right way to achieve this, I can reflect upon Anzaldúa's essay to see the wrong way to approach language barriers.

For one, she explains how shame is deeply connected to language, and as a writing consultant, it is my job to do all that I can to avoid creating shame in others due to language differences. I was reminded that language is deeply interwoven within a person.... It is my job to elevate the identity formed in a language, not to mute it or challenge its value or purpose.

This essay also reaffirmed my understandings of the intersections between racism, sexism, and classism within language oppression discourses. Anzaldúa reminded me that when dealing with language oppression, you are also leaning into histories of sexism and classism. As a writing consultant who wants to approach consultations through a feminist lens, the way I handle language shapes much of my practice. Traditional, patriarchal approaches to academia assert strict binaries as a way of establishing order. ...My desire to practice feminist approaches in the Writing Center has been challenged by my own upbringing within traditional structures of academia....Oppression happens easily through language, and we must be careful to fight against the past in order to embrace not only the diversity of language usage but also the identities of the people who speak.

Andie's response focuses on the concept of the interconnectedness of language variation and linguistic identity. Her reflections take on issues of intersectionality to orient herself to a deeper understanding of language oppression. Andie identifies the tension (troublesome knowledge) with long held patriarchal ideologies of her upbringing and education and juxtaposes it with intention to practice feminist approaches. Echoing Anzaldúa's assessment that evaluating a language is evaluating its speakers, Andie locates the moment of tension in "the way [she] handle[s] language". She concludes in a resolution to "fight ... in order to embrace not only the diversity of language usage 
Volume 30, 2020

http://journals.sfu.ca/cjsdw

but also the identities...." While this notion of fighting wasn't fully unpacked, I learned that Andie's process was intense and involved conversations with multiple colleagues, mentors, and faculty members.

Kindra's Response:

Reading Vershawn Ashanti Young's article "Should Writers Use They Own English?" really hit home for me. Growing up in Hawai'i has exposed me to a multitude of languages, which eventually blended into an intersectional dialect referred to as "pidgin." After all, Hawai'i is known as the melting pot of the pacific. Because of my home's history with immigration and oppressive plantations, Portuguese, Korean, Japanese, Filipino, Hawaiian, and Chinese languages have all blended into the dialect known as "pidgin", which helped immigrants communicate with each other in the workplace. I think this is an excellent example of how Young's term "code meshing" proves to enhance rather than inhibit communication. The inclusive use of terms from all languages gave the local community a better awareness and understanding of each other's cultures. The intersectional aspects of pidgin helped promoted unity instead of alienation. To me, language is a vital part of identity. Myself being Portuguese, Japanese, Hawaiian, Filipino, and Hungarian, I hold speaking pidgin as a vital aspect of my identity. Therefore, Stanley Fish's proposal to universalize the English language as the standard and most formal way to write erases hundreds of identities from communication.

Young comments on Fish's point that "People make themselves targets for racism if and when they don't write and speak like he [Fish] do" (61). I agree with him when he exposes oppressive attitudes as the reason for this racism, rather than the act of writing in one's own dialect. It's contradictory to expect someone to speak and write in their native language only at home. This enforces dangerous pressures to assimilate. Language doesn't cause oppression; it is the views around the language that does. Fish is an example of a person employing an oppressive view going into reading dialects. To celebrate diversity in language and writing, people must have a more open and empathetic attitude while trying to understand the ideas of over cultures.

I'm reminded of one of my consultations that exemplifies the way in which these oppressive attitudes can instill fear in minority students. A student explained to me that she purposely made an appointment with me because she saw I was from Hawai'i and knew I would understand her struggles with grammar because of my familiarity with pidgin and Hawai'i culture. I was very touched that she saw me as an ally and was happy to support her as a writer and fellow local. However, I was sad to see how much our culture had given her anxiety in the academic world. After reading Young's article, I want to tell her how code meshing can work to her advantage and help add flavor and style to writing. I don't ever want students to think use of 
Volume 30, 2020

http://journals.sfu.ca/cjsdw

their own culture is what hinders their academic writing. It's their identity. Identity has just as much an important role in writing as grammar, if not more. I am a strong advocate for maintaining identity and meaning over "pure standard English."

Kindra's response questions the politics of oppression in limiting the use of "home language" to the private sphere and introduces a passionate argument of what matters more--identity and meaning or pure standard English. Her reflection echoes the concept that multilingualism should function as a resource (just as hers functioned as a resource to support her client). The reflection also regrets contexts where, due to linguistic discrimination, a multicultural identity is considered a liability. The threshold concept of multilingualism as a resource in tension with requirements of standardized English is negotiated throughout her response and her practice in the Writing Center.

Analyzing the common threads in these responses reveal the level to which these concepts of language variation, language and identity, and multilingualism as a resource were indeed "new knowledge" to the consultants. I'm compelled to admit that in my previous version of this course, I failed to appreciate how students who have been described as "good writers" remained in the dark about these linguistic realities.

Consultants' responses identified areas of troublesome knowledge where they marked the need to "unlearn," and "challenge" one's assumptions. These were the moments where they focused on resisting the monolingual language ideologies of academic writing. The responses also evidenced the tendency of threshold concepts to be integrated and to have potential for transformative practice. All responses evidenced efforts of integration and reflection on personal experiences and offered a commitment to question old practices and to adopt more inclusive practices, even in situations when questions remained on what an inclusive practice should look like.

\section{Rewarding Reflective Practices: Using Portfolios for Evaluation}

I grew to appreciate the challenges writing consultants experience in balancing their practice with their clients' desires, institutional responsibilities, and anxiety over whether they are doing a good job. I also grew to appreciate the reality that many of them have not experienced anti-oppressive writing pedagogies in their own education and that the practice that they are encouraged to follow is one that counters what they have learned all along. A brilliant writing consultant called it a crisis of imagination of practicing something they have never experienced as students. 
Volume 30, 2020

http://journals.sfu.ca/cjsdw

In Fall 2017, consultants' anxieties about the grade and the complexities of practicing what they are learning were overwhelming. When acquiring new concepts that challenged their practice, consultants felt some guilt and obligation to defend previous decisions they made in their sessions. This made for an environment where learning new concepts felt stressful. For example, when in week eight, a consultant learned a new way to address a grammar question they addressed in week four, they experienced guilt for not getting it right and/or frustration for not being taught it in advance. It became clear that I needed to integrate a system to avoid perfectionism and account for learning as a developing process. In Fall 2018, I introduced a portfolio system for assessment, where a holistic evaluation based on consultants' self-assessment replaced my instructor-centered weekly grading. I still responded to weekly assignments and provided feedback on drafts. However, the portfolios gave consultants plenty of time and space to revisit older assignments and consultation with a new lens, while getting feedback along the way. Consultants could select to revise reflection papers, observations, and even major assignments. They were also asked to choose which learning outcomes were most meaningful to them and which they need more support with. The portfolio approach went a long way toward normalizing changes in perspective and practices as a feature of continued learning (rather than a damning indication of initial failures).

While reflections are often used to prompt self-assessment, expand strategies, and improve practices, writing center scholarship reminds us that the outcomes of reflections may vary. Hall (2011) urges us to develop opportunities for meaningful reflective practices for tutors that go beyond producing documents of surveillance. His work demonstrates the potential of reflection to establish a community of practice. In setting up the portfolio, I was careful to explain the pedagogical rationale as establishing a supportive community for their practice: to explore how the center, the readings, consultations, colleagues, mentors, and clients have contributed to their learning and what they hope to further develop in their ongoing practice.

Reflections have been also employed to support our commitment to anti-oppressive pedagogies and inclusive practice (Grimm, 1999; Okawa, et.al, 2010; Greenfield \& Rowan, 2011; Blazer, 2015). Greenfield and Rowan argue for the necessity to shift our pedagogies of coverage to critical pedagogies where understanding oneself--understanding the role of culture, gender, colonialism, power-- translates into understanding one's agency, which “is critical to [the tutors'] ability to help writers do the same" (Greenfield \& Rowan, 2011, p. 127). 
Volume 30, 2020

http://journals.sfu.ca/cjsdw

The portfolio system has allowed space for the consultants' responses to be part of a continuous conversation--one that takes into account initial positions, response to scholarship, analysis of consultations, reflections, and conversation with the instructor and colleagues (Peters \& Robertson, 2007; Yancey, 2004). Noticing moments of discomfort and intentionally learning to welcome them as natural and worthy of analysis and reflection, rather than embarrassing byproducts that should be avoided becomes a key in facilitating transformative learning. In this context, mistakes are allowed, and revisions are welcome.

The portfolios captured how the consultants operationalized the threshold concepts they had identified to inform their practice. Additionally, they reflected each consultant's individual and collective journey in this learning. While the Fall 2017 cohort of peer consultants were mostly eager to learn the correct response to addressing grammar concerns of ESL students, the Fall 2018 cohort demonstrated much flexibility in knowing that an ethical practice requires a thoughtful analysis of the rhetorical context and the clients' goals and agency. Their portfolio cover letters demonstrated this flexibility and their tendency to critically question writing center practices that privilege monolingualism. While the challenge of working with multilingual writers remained, the reasons for these challenges shifted significantly from issues regarding the client's level of preparedness, anxiety about grammar, and lack of time to address issues to a critical lens that unpacked the problems in terms of marginalizing and oppressive institutional practices. In demonstrating commitment to linguistic diversity, a consultant writes "Collaborating with ESL clients constitutes an additional challenge due to the institutional expectations of academic language."

While the context of directive/non-directive dichotomies offered almost paralyzing contexts for consultants, acquiring threshold concepts allowed for productive flexibility. The lack of a fixed script for each consultation didn't undermine the consultants' sense of confidence in supporting multilingual writers. While introducing notions of rhetorical grammar made for longer conversations between consultants and clients to decide on revisions, these decisions were made with more confidence than the ones previously made with the pre-determined conclusion to conform to standardized English.

In her cover letter, Tessa reflected on the conversations she had with the assistant director when she wasn't comfortable following the request of a student to "fix" grammar. Although she had honored the client's request and explained the grammar conventions, Tessa described her discomfort 
Volume 30, 2020

http://journals.sfu.ca/cjsdw

about changing her client's voice without having a critical conversation with the client about the standardized conventions. She reflected on the process of balancing different concerns and concluded by describing her current practice "Now when I work with multilingual students, I make sure to ask them if their intention is to follow the standardized American academic convention, and explain to them the reason I'm asking is because they do have choice and agency in the matter. I make sure to allow them space to decide for themselves what feels safe and comfortable in terms of subverting conventions in their writing and work to ensure that they understand the worth of their own voice." While Tessa continues to challenge racist institutional setting where World Englishes are riskier, she has found a way to support writers in performing and negotiating their linguistic identities. This stance goes far beyond the dichotomy of directive/non-directive to one that centers the rhetorical goals of the clients.

Kindra reflects on her multiple efforts to go beyond monolingual language assumptions in encouraging her multilingual clients to code-mesh. She draws on conversations she had with mentors, her research project on international writing centers, and her work with clients. She summarizes her goal as "As this course comes to a close, my ultimate goal as a writing consultant prevails: to inspire each student's confidence and passion in writing, as an author's voice is the most powerful mode of autonomy, communication, and change." Kindra's reflections are grounded in understanding multilingualism as a linguistic resource interconnected with writer's voice and identity. To her, negotiating autonomy and achieving authentic communication is a call for change that decenters standardized monolingual texts.

An outcome that I didn't expect is how the consultants took the course materials beyond the class in multiple conversations with colleagues and mentors and beyond writing center. Andie for example, scheduled an appointment with a faculty member in the English Department to discuss how oppressive "standard" English can be. Perhaps the benefits of the portfolio can be summarized in how it afforded space for an ongoing process that is neither perfect nor complete.

\section{Moving Forward and Next Steps}

Indeed, through this process of engaged reflection on the consultants' learning and my own role as a director and instructor, I realized that this process is a never-ending effort to keep learning and 
Volume 30, 2020

http://journals.sfu.ca/cjsdw

unlearning6. I've made the course revisions in collaboration with consultants from Fall 2017 cohort and I know that I will continue to examine moments of failure, confusion, and limitation as part of my own reflective practice. I expect that incoming cohorts of consultants will support the continued process of my learning as I facilitate theirs.

Orienting writing center practice toward a commitment to inclusivity of multilingualism and multiliteracies should not stop at clients. As Nancy Grimm (2011) argues, instead of focusing on students as the sites of instruction and change, we should make commitments to creating "better institutions." Grimm's postmodernist critique calls the university to change its views of multilingualism and to become inclusive institution. A major source of frustration and agony for the writing consultants remained how to support a client in negotiating teaching practices and grading criteria that continue to perpetuate racist and colonizing assumptions about language and linguistic diversity. Understanding that the new conceptual frameworks are not necessarily shared ones, the consultants expressed obligation to inform institutional practices and to share their learning and materials with campus community. Writing centers do not operate in an institutional vacuum. Our conversations about anti-oppressive work has generated collaborative connections with colleagues teaching writing in the core curriculum, writing studies seminars, and other student-centered scholarship programs. Although this article focuses on consultants' education, the work of supporting a multilingual turn in composition studies and in education expands far beyond the writing center. This collaborative work holds rewarding potential for transformative practices that support our institutions in their commitment to social justice for multilingual learners.

\section{References}

Adler-Kassner, L., Wardle, E. (2015). Naming what we know: Threshold concepts of writing studies. Logan: Utah State University Press.

Anzaldúa, G. (2001). "How to tame a wild tongue" (1987). In K. Ronald and Ritchie, J (eds). Available Means: An Anthology of Women's Rhetoric(s) (pp357-365). University of Pittsburgh Press.

\footnotetext{
${ }^{6}$ This article is part of a multi-cohort study of the different revisions of tutor education curriculum. In subsequent work I explore how the tutor education course led to changes in practices and programming.
} 
Volume 30, 2020

http://journals.sfu.ca/cjsdw

Bailey, S. K. (2012). Tutor handbooks: Heuristic texts for negotiating difference in a globalized world. Praxis: A Writing Center Journal, 9(2), 1-8.

Bawarshi, A., \& Pelkowski, S. (1999). Postcolonialism and the idea of a writing center. The Writing Center Journal, 19(2), 41-58.

Blazer, S. (2015). Twenty-first century writing center staff education: Teaching and learning towards inclusive and productive everyday practice. The Writing Center Journal, 35(1), 17-55.

Boquet, E. H. (1999). "Our little secret": A history of writing centers, pre- to post-open admissions. College Composition and Communication, 50(3), 463-482.

Brooks, J. (1991). Minimalist tutoring: Making the students do all the work. Writing Lab Newsletter, 15(5), $1-4$.

Bruce, S. \& Rafoth, B. A. (2009). ESL writers: A guide for writing center tutors (2nd ed.). Portsmouth, NH: Portsmouth, NH: Boynton/Cook Publishers.

Cameron, D. (1995). Verbal hygiene. London; New York: Routledge.

Canagarajah, A. S. (2006). Toward a writing pedagogy of shuttling between languages: Learning from multilingual writers. College English, 68(6), 589-604.

Canagarajah, A. S. (2013). Negotiating translingual literacy: An enactment. Research in the Teaching of English, 48(1), 40-67.

Canagarajah, S. (2016). Translingual writing and teacher development in composition. College English, 78(3), 265-273.

Carino, P. (1995). Early writing centers: Toward a history. The Writing Center Journal, 15(2), 103115.

Condon, F. (2012). I hope I join the band narrative, affiliation, and antiracist rhetoric. Logan, UT: Utah State University Press.

Denny, H. (2010). Queering the writing center. The Writing Center Journal, 30(1), 95-124. 
Volume 30, 2020

http://journals.sfu.ca/cjsdw

Dinitz, S. (2018). Changing peer tutors' threshold concepts of writing. WLN: A Journal of Writing Center Scholarship, 42(7-8), 2-9.

Donahue, C. (2016). The "trans" in transnational-translingual: Rhetorical and linguistic flexibility as new norms. Composition Studies, 44(1), 147.

Greenfield, L. \& Rowan, K. (2011). Writing centers and the new racism: A call for sustainable dialogue and change. Logan, UT: Utah State University Press.

Greenfield, L. (2011). The "standard English" fairy tale: A rhetorical analysis of racist pedagogies and commonplace assumptions about language diversity. In L. Greenfield \& Rowan, K. (Eds). Writing centers and the new racism: A call for sustainable dialogue and change (pp 34-60). Logan, UT: Utah State University Press.

Greenfield, L. (2019). Radical writing center praxis: A paradigm for ethical political engagement. Logan, UT: Utah State University Press.

Grimm, N. M. (1999). Good intentions: Writing center work for postmodern times. Portsmouth, NH: Portsmouth, NH: Boynton/Cook-Heinemann.

Grimm, N. M. (2009). New conceptual frameworks for writing center work. The Writing Center Journal, 29(2), 11-27.

Hall, R. M. (2011). Theory in/to practice: Using dialogic reflection to develop a writing center community of practice. The Writing Center Journal, 31(1), 82-105.

Horner, B., NeCamp, S., \& Donahue, C. (2011). Toward a multilingual composition scholarship: From English only to a translingual norm. College Composition and Communication, 63(2), 269-300.

Inoue, A. B. (2015). Antiracist writing assessment ecologies: Teaching and assessing writing for a socially just future. Fort Collins, CO: The WAC Clearinghouse; Anderson, SC: Parlor Press.

Lippi-Green, R. (2012). English with an accent: Language, ideology and discrimination in the united states (2nd ed.). London; New York: Routledge. 
Volume 30, 2020

http://journals.sfu.ca/cjsdw

Nowacek, R.S., \& Hughes, B. (2015). Threshold concepts in the writing center: Scaffolding the development of tutor expertise. In L. Adler-Kassner \& Wardle, E. (Eds.), Naming what we know: Threshold concepts of writing studies (pp171-185). Logan, UT: Utah State University Press.

Okawa, G. Y., Fox, T., Chang, L. J. Y., Windsor, S. R., Chavez, F. B., \& Hayes, L. (2010). Multi-cultural voices: Peer tutoring and critical reflection in the writing center. The Writing Center Journal, $30(1), 40-65$.

Peters, B., \& Robertson, J. F. (2007). Portfolio partnerships between faculty and WAC: Lessons from disciplinary practice, reflection, and transformation. College Composition and Communication, 59(2), 206-236.

Smitherman, G. \& Villanueva, V. (2003). Language diversity in the classroom: From intention to practice. Carbondale: Southern Illinois University Press.

Yancey, K. B. (2004). Postmodernism, palimpsest, and portfolios: Theoretical issues in the representation of student work. College Composition and Communication, 55(4), 738-761.

Young, V. A. (2011). Should writers use they own English? In L. Greenfield \& Rowan, K. (eds). Writing centers and the new racism: A call for sustainable dialogue and change (pp61-72). Logan, Utah: Logan, UT: Utah State University Press. 